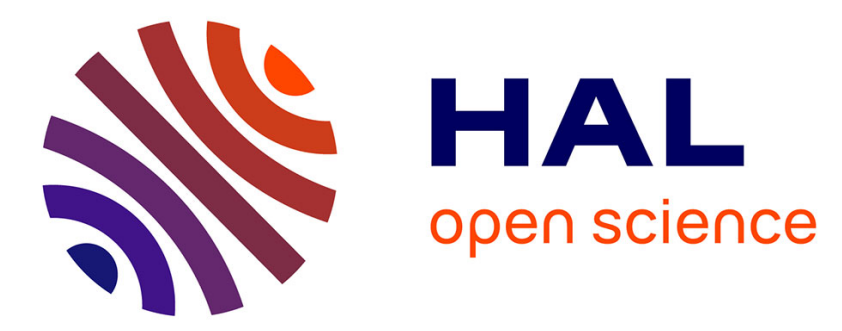

\title{
New Insight into Cluster Aggregation Mechanism during Polymerization-Induced Self-Assembly by Molecular Dynamics Simulation
}

Fabrice Brunel, Jennifer Lesage de La Haye, Muriel Lansalot, Franck D'agosto

\section{- To cite this version:}

Fabrice Brunel, Jennifer Lesage de La Haye, Muriel Lansalot, Franck D'agosto. New Insight into Cluster Aggregation Mechanism during Polymerization-Induced Self-Assembly by Molecular Dynamics Simulation. Journal of Physical Chemistry B, 2019, 123 (30), pp.6609-6617. 10.1021/acs.jpcb.9b03622 . hal-02408548

\author{
HAL Id: hal-02408548 \\ https://hal.science/hal-02408548
}

Submitted on 12 Nov 2020

HAL is a multi-disciplinary open access archive for the deposit and dissemination of scientific research documents, whether they are published or not. The documents may come from teaching and research institutions in France or abroad, or from public or private research centers.
L'archive ouverte pluridisciplinaire HAL, est destinée au dépôt et à la diffusion de documents scientifiques de niveau recherche, publiés ou non, émanant des établissements d'enseignement et de recherche français ou étrangers, des laboratoires publics ou privés. 


\section{New Insight into Cluster Aggregation Mechanism during Polymerization-Induced Self-Assembly by Molecular Dynamics Simulation}

Fabrice Brunel, ${ }^{, \dagger}$ Jennifer Lesage de la Haye, ${ }^{\ddagger}$ Muriel Lansalot, ${ }^{\dagger}$ and Franck

$$
\text { D'Agosto }^{\dagger}
$$

†Univ. Lyon, Université Claude Bernard Lyon 1, CPE Lyon, CNRS, C2P2, 43 Bvd. du 11 Novembre 1918, F-69616 Villeurbanne, France

$\ddagger$ Univ Lyon, Université Claude Bernard Lyon 1, CNRS, CNES, ArianeGroup, LHCEP, Bât. Raulin, 2 rue Victor Grignard F-69622 Villeurbanne, France

E-mail: fabrice.brunel@univ-lyon1.fr 


\begin{abstract}
Investigations of polymerization-induced self-assembly in emulsion were conducted using MD simulations. Using umbrella sampling and the Weighted Histogram Analysis Method (WHAM) algorithm, we calculated the interaction free energy between different self-assembled copolymer aggregates. In the presence of poly(ethylene glycol) (PEG) at $80{ }^{\circ} \mathrm{C}$ side chains an attractive interaction between the copolymer micelles is observed. This attractive well is followed, in some case, by a repulsive barrier depending on the position of the PEG side-chains. The strength of this repulsive barrier controls the aggregation kinetics: a strong repulsive barrier leads to slower aggregation rate and thus larger and denser clusters (i.e. reaction limited cluster aggregation). Theses clusters then coalesce into large vesicles due to the presence of interstitial water molecules in the cluster. Inversely, a weak repulsive barrier causes a rapid aggregation which gives loose and ramified clusters (i.e. diffusion limited cluster aggregation) that coalesce after swelling with hydrophobic monomer, leading to tubular nano-structures and small vesicles. This new mechanism approach can explain the change of morphology from spheres to fibers and vesicles depending on the polymer architecture in the case of polymerization-induced self-assembly (PISA) in emulsion.
\end{abstract}

\title{
Introduction
}

The development of reversible-deactivation radical polymerization (RDRP) is considered as a major step forward for the design of tailor-made polymer architectures. ${ }^{1-7}$ Among the various accessible architectures, amphiphilic block copolymers represent probably the most studied systems since they can self-assemble in water to form a variety of nano-structures. ${ }^{8}$ Multiple morphologies of self-assembled block copolymers were first obtained by Eisenberg et al. using the solvent displacement method with well-defined amphiphilic block copolymers prepared by anionic polymerization followed by post-synthesis modification. ${ }^{9}$ The change of morphology from spheres to fibers or vesicles can be rationalized in terms of an increase in 
the packing parameter, $P$, which is given by the equation:

$$
P=\frac{\nu}{a_{0} l_{c}}
$$

Where $\nu$ and $l_{c}$ are the volume and the length of the hydrophobic block respectively, and $a_{0}$ is the effective interfacial area of the block junction. This concept, originally introduced by Israelachvili and co-workers ${ }^{10}$ to explain surfactant self-assembly, was later extended to diblock copolymer self-assembly by Antonietti and Förster. ${ }^{11}$ It is generally accepted that spherical micelles are favoured when $P \leq 1 / 3$, fibers are produced when $1 / 3<P \leq 1 / 2$, and vesicles are formed when $1 / 2<P \leq 1.0$.

In the field of emulsion polymerization, the need for the production of self-stabilized latex without the use of molecular surfactant has led to the establishment of strategies to produce amphiphilic block copolymers directly in water. These self-assembly techniques have further face the need for the preparation of large amounts of materials and the need for better defined and predictable morphologies. ${ }^{12,13}$ One of the developed strategies is based on the use of a hydrophilic living polymer precursor prepared via RDRP that is extended with a hydrophobic second block, leading to amphiphilic block copolymers that self-assemble in situ into self-stabilized nano-objects. ${ }^{14-20}$ This approach, coined polymerization-induced self-assembly (PISA), can produce diblock copolymer nanoparticles in the form of either spheres, fibres or vesicles using either dispersion or emulsion polymerization. Aqueous dispersion PISA relies on chain-extension of a hydrophilic polymer with a water-soluble monomer which, upon polymerization, forms a water-insoluble block. This method enables the production of various copolymer morphologies such as spheres, worms or vesicles. ${ }^{16,18}$ On the other hand, PISA in emulsion uses a water-immiscible monomer, although exhibiting a low solubility in water, to produce the hydrophobic core-forming block. According to many literature reports, and contrary to dispersion polymerization, PISA in emulsion very often leads to spherical mor- 
phologies irrespective of the polymerization degree of the hydrophobic block. ${ }^{19,21-24}$ There seems to be a consensus as to the mechanism of formation of nano-objects using PISA. Small spherical micelles appear at small conversion followed by their transformation into other morphologies. The formation of fiber-like structures is supposed to be the result of "worms" made of strings of micelles. Then, the fusion of these "worms" forms intermediate "jellyfish" structures that enclose themselves into vesicles. ${ }^{25,26}$

Recently, new insights into the PISA process were provided by precisely controlling the position of poly(ethylene glycol) (PEG), side chains within the hydrophilic block obtained from Reversible Addition-Fragmentation Chain Transfer (RAFT) polymerization and later defined as a macroRAFT. ${ }^{27}$ Unexpectedly, the introduction of PEG side chain leads to the formation of vesicles as the predominant morphology. According to the packing parameter, the presence of side chains should increase the effective interfacial area of the block junction $\left(a_{0}\right)$ and thus lower the packing parameter which should favour a spherical morphology. An alternative way to form vesicles relies on the formation of crew-cut micelles upon an increase of hydrophobic block polymerization degree. ${ }^{28}$ However, the presence of PEG branched onto the hydrophilic block which increases the corona thickness, should be unfavorable to the formation of crew-cut micelles leading to more star-like micelles. Such slight modifications of the polymer architecture resulting in a strong and unusual effect on the morphology offer a great opportunity to probe the impact of the hydrophilic block architecture on the formation of specific morphologies in PISA using molecular dynamics (MD). Following previous simulations that show the self-assembly of copolymers into small micelles (with an average number of copolymers per micelles, $n_{\text {agg }}$, around 10) during the first moment of the process, ${ }^{27}$ we decided to explore the fate of these micelles and how the final vesicular morphology can be obtained. To do so, we used first (i) the estimation of the coalescence and diffusional growth rate using the theory of Brownian encounter, and second (ii) MD simulations using the umbrella sampling method and the Weighted Histogram Analysis Method (WHAM) to calculate the interaction profile between the micelles. This simulation technique is commonly 
used to obtain the energy landscape for ligand-protein binding energy ${ }^{29-33}$ and to generate free energy profiles for the conformational transition of protein molecules. ${ }^{34-37}$ Recently, this simulation technique was applied to study polymer adsorption and shown to be very useful in the case of LLDPE adsorption onto graphene. ${ }^{38}$ Current findings suggest that it can also be used for studying interaction forces between colloidal particles. From these information we were able to propose in this paper a scenario explaining vesicles formation in emulsion PISA.

\section{Materials and Methods}

Molecular Dynamics Simulations. Molecular Dynamics (MD) simulations were carried out using the GROMACS package, version 5.1.4. ${ }^{39-42}$ Martini coarse-grained force field ${ }^{43}$ was applied to polystyrene, ${ }^{44}$ poly(ethylene glycol $)^{45}$ (PEG) and poly $(N$-acryloylmorpholine) (PNAM) (Figure 1). The Martini coarse-grained model of PEG usually require to enhance the self-interaction between the PEG beads $\left(\epsilon_{P E G / P E G}=3.5 \mathrm{~kJ} \cdot \mathrm{mol}^{-1}\right)$ and the interaction between PEG beads and water beads $\left(\epsilon_{P E G / \text { water }}=3.5 \mathrm{~kJ} \cdot \mathrm{mol}^{-1}\right)$ to $\epsilon_{P E G / P E G}=4.5$ $\mathrm{kJ} \cdot \mathrm{mol}^{-1}$ and $\epsilon_{P E G / \text { water }}=4 \mathrm{~kJ} \cdot \mathrm{mol}^{-1}$, respectively. ${ }^{45}$ However, at $80{ }^{\circ} \mathrm{C}$, an LCST-type phase separation of PEG in water can occur due to the dehydration via the disruption of hydrogen bonding interaction between the oxygen atom of the ether moiety and water. ${ }^{46}$ Therefore in our simulations the interaction between PEG beads and water beads was kept to $\epsilon_{P E G / \text { water }}=3.5 \mathrm{~kJ} \cdot \mathrm{mol}^{-1}$ in order to mimic the hydrophobic behaviour of the PEG at 80 ${ }^{\circ} \mathrm{C}$. PNAM martinized force field was parametrized on atomistic simulations using OPLS allatoms force fields as described by Marrink et al. ${ }^{43}$ and verified by comparing coarse grained and SAXS-measured polymer dimensions, namely the radius of gyration and the persistence length (see supplementary material). Short-range nonbonded interactions were cut off at 1.4 $\mathrm{nm}$ and dispersion correction was applied to energy and pressure terms to account for truncation of Van der Waals terms. ${ }^{47}$ Periodic boundary conditions were applied in all directions. 


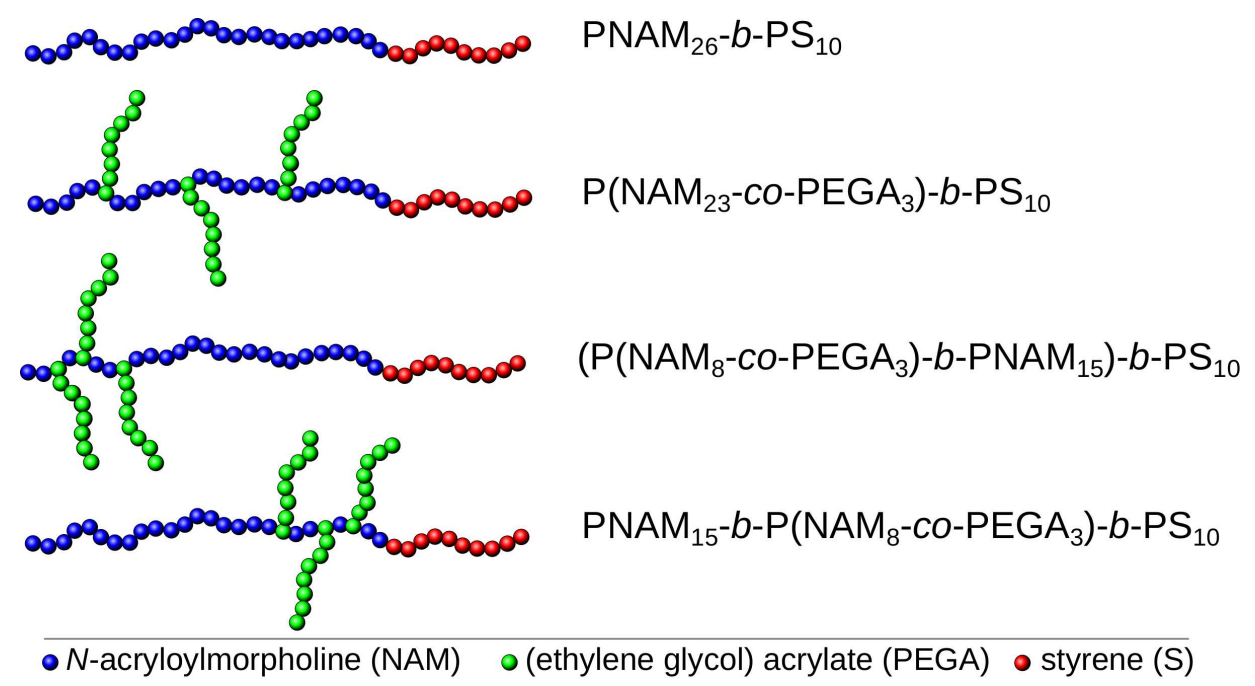

Figure 1: Topologies of the amphiphilic block copolymers used for the simulation. The architectures are designed to reproduce experimental data from Lesage de la Haye et al.. ${ }^{27} \mathrm{~A}$ 10 styrene units hydrophobic block is used since it corresponds to the onset of the nucleation and the formation of the first micelles.

Umbrella sampling. First a dozen of macroRAFT molecules with 10 styrene units were equilibrated in a $10 \times 10 \times 10 \mathrm{~nm}$ box, then the aggregation was forced by pulling the styrene beads toward the center of the box using the pull code option available on the GROMACS software. The number of styrene units (i.e. 10 units) is twice the critical chain length required for considering PS oligomers no longer soluble in the aqueous phase $\left(j_{\text {crit }}=5\right)$ and thus sufficient to create small stable micelles. ${ }^{48}$ The stability of the corresponding micelles has been verified on a $1 \mu$ s simulation (data not shown) which is suitable for measuring intermicelle interaction using umbrella sampling. Two micelles were then placed in a rectangular box $(10 \times 10 \times 30 \mathrm{~nm})$ with varying distance between the center of masses of the polystyrene cores (from 5 to $15 \mathrm{~nm}$ every $0.5 \mathrm{~nm}$ ) (Figure 2). Following steepest descents minimization, all boxes were equilibrated in two steps. The first phase involved simulating for $500 \mathrm{ps}$ under a constant volume (NVT) ensemble and using position restraints on the polystyrene cores. Temperature was maintained at $355 \mathrm{~K}\left(82^{\circ} \mathrm{C}\right)$ using the Berendsen weak coupling 
method. ${ }^{49}$ Following NVT equilibration, 20 ns of constant-pressure (NPT) equilibration were performed, also using weak coupling to maintain pressure isotropically at 1.0 bar with position restraints applied to polystyrene cores. Production MD simulations were conducted for $10 \mathrm{~ns}$ with the harmonic force constant of $100 \mathrm{~kJ} \cdot \mathrm{mol}^{-1} \cdot \mathrm{nm}^{-2}$ between the two polystyrene hydrophobic cores. For this data collection period, the Nose-Hoover thermostat was used to maintain temperature, ${ }^{50,51}$ and the Parrinello-Rahman barostat was used to isotropically regulate pressure. ${ }^{52,53}$ Analysis of results was performed with the WHAM algorithm.

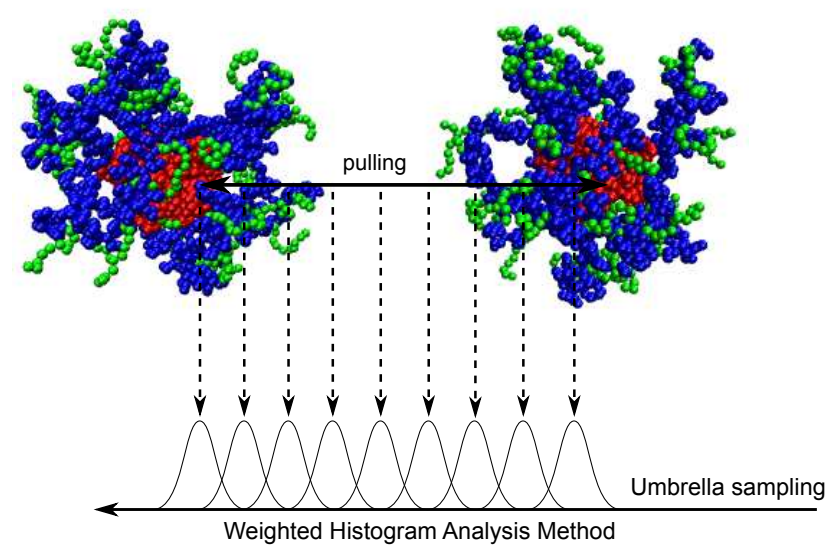

Figure 2: Illustration of the umbrella sampling simulation / Weighted Histogram Analysis Method.

\section{Results and Discussion}

Previous MD simulations, using a rather simple coarse-grain model, suggest that the change of morphology induced by the presence and the position of PEGA units into a hydrophilic PNAM macroRAFT might be the result of a modification of self-assembly kinetics. ${ }^{27}$ Recent MD simulations, using dissipative particle dynamic (DPD), ${ }^{54,55}$ also suggest that the polymerization kinetics has an impact on the final morphology. Therefore, we decided to explore in more detail the kinetic aspect of the self-assembly process. First, several observa- 
tions can be made based on our previous model: when enough hydrophobic monomer units were polymerized ( $\mathrm{DP} \approx 10$ in the case of styrene) the self-assembly started very rapidly $(\approx 100 \mathrm{~ns})$ and led to the formation of small micelles of diblock copolymers $\left(n_{\text {agg }} \approx 10\right)$. These micelles remained stable during the timescale of a typical MD-simulation $(<1 \mu \mathrm{s})$. In emulsion, further growth of these micelles depends on two mechanisms: (i) diffusional growth (i.e. the diffusion of the styrene monomer from the droplets to the micelles), and (ii) the coalescence where two micelles merge during contact to form a single daughter micelle. A simple calculation from the theory of Brownian motion allows discriminating between these two phenomena. First we can estimate the coalescence rate by calculating the collision frequency between small micelles $(J(i \rightarrow i))$ to be around $10^{5}$ collisions $\cdot \mathrm{s}^{-1}$.

$$
J(i \rightarrow i) \approx \frac{2 \phi}{\pi \tau}
$$

With $\tau=\frac{\eta R^{3}}{k_{B} T}$ and the volume fraction $\phi=\left(\frac{4}{3}\right) \pi R^{3} C$. Where $\eta$ is the viscosity of water $\left(1 \times 10^{-3} \mathrm{~Pa} \cdot \mathrm{s}\right), \mathrm{R}$ the radius of the aggregate $(\approx 2.5 \mathrm{~nm}$, half of the minimum separation distance attainable between the center of mass of two micelles, i.e. the lowest value of the $\mathrm{x}$-axis in Figure 3$), k_{b}$ the Boltzmann constant $\left(1.38 \times 10^{-23} \mathrm{~J} \cdot \mathrm{K}^{-1}\right)$, $\mathrm{T}$ the temperature $(355 \mathrm{~K})$, C the micelle concentration $\left(6 \times 10^{22}\right.$ micelle $\left.\cdot \mathrm{m}^{-3}\right)$. The micelle concentration is derived from the macroRAFT concentration $\left(2.78 \times 10^{-2} \mathrm{~mol} \cdot \mathrm{L}^{-1}\right)$ with an average number of copolymers per particle $n_{\text {agg }}$ of 10 .

It is also useful to estimate the diffusional growth rate of these small micelles ( $i$-particles) in a solution of monomers ( $j$-particles). In this case the collision frequency is approximately:

$$
J(j \rightarrow i) \approx 4 \pi D_{j} R_{i} c_{j}
$$

With $D_{j}=\frac{k_{B} T}{6 \pi \eta R_{j}^{3}}$; where $R_{j}=0.5 \mathrm{~nm}, R_{i}=5 \mathrm{~nm}$ and the monomer concentration $c_{j}$ $=3 \times 10^{-3} \mathrm{~mol} \cdot \mathrm{L}^{-1}=1.74 \times 10^{24}$ molecules $\cdot \mathrm{m}^{-3}$ derived from the solubility of styrene in 
water.

Therefore the increase in styrene concentration from diffusional growth (i.e. styrenemicelles collision frequency: $J(j \rightarrow i) \approx 10^{7}$ collisions $\left.\cdot \mathrm{s}^{-1}\right)$ is about the same order of magnitude as the increase of styrene concentration from the coalescence (i.e. micelles-micelles collisions: $\left(J(i \rightarrow i) \approx 10^{5}\right.$ collisions $\left.\cdot \mathrm{s}^{-1}\right)$ since there are roughly hundred styrene units per micelle. This means that the micelles can grow from both of these mechanisms. One should note that this will not be the case in dispersion polymerization, where the monomer is soluble in the continuous phase at a concentration of around $10^{-1} \mathrm{~mol} \cdot \mathrm{L}^{-1}$ compared to the value of $3 \times 10^{-3} \mathrm{~mol} \cdot \mathrm{L}^{-1}$ in emulsion polymerization. Therefore, in this case, there is a hundred times more monomer in solution and the monomer-micelles collision frequency is estimated at around $10^{9}$ collisions $\cdot \mathrm{s}^{-1}$, which is a hundered times greater than the micellesmicelles collision frequency. Therefore, in dispersion PISA, micelles-micelles collisions are negligible compared to the swelling of the hydrophobic phase by the monomer. In short, in the case of emulsion PISA, one has a "slow" flow of monomer which stops only when all the monomer reservoir droplets are consumed, whereas in dispersion PISA the diffusional growth of the micelles with the monomer is extremely fast but will rapidly reach an equilibrium (the monomer being shared between the hydrophilic and hydrophobic phases). This fast swelling of the micelle could lead to their rapid destabilization and their coalescence as small particles which can later evolve into other morphologies via a mechanism similar to the one described below but on a larger length scale. Therefore, the mechanism presented here will focus mainly on emulsion PISA where the coalescence between small copolymer micelles can be observed, even so it could provide some interesting insight as to the dispersion PISA mechanism.

Having demonstrated above that a micelle coalescence growth mechanism is possible (i.e. coalescence growth rate similar to the diffusional growth of styrene monomer from droplets) we decided to study the interaction between such aggregates by performing umbrella sam- 
pling simulations. These MD simulations were performed using a coarse-grain model described in the materials and methods section. The $N$-acryloylmorpholine monomers were parametrized using all-atom simulation and polymer conformation (measured by SAXS) for bonded and non-bonded interactions, respectively. One should also note that the above calculation assumed a 100\% collision efficiency (i.e. all collisions lead to the fusion of the micelles), which is hardly realistic considering the steric stabilization provided by the hydrophilic block. Such steric repulsion is indeed observed in the case of a pure PNAM hydrophilic block $\left(\mathrm{PNAM}_{26^{-}} b-\mathrm{PS}_{10}\right.$ ), where the calculated energy profile shows purely repulsive forces (see Figure 3a). The interpretation is quite straightforward and illustrated in Figure 4a. The first micelles formed are very stable and do not coalesce with each other. However, the diffusional growth still happens, and these micelles swell with styrene monomer within their hydrophobic core and increase their radius while the number of hydrophilic segments remains constant. At a certain point, the number of hydrophilic chains per surface become too low to ensure sufficient steric stabilization and the coalescence will happen so that two aggregates can share their hydrophilic segments. This process will repeat itself up to the depletion of the styrene reservoir droplets. Note that, at first approximation, the number of chains double at each step and thus $n_{\text {agg }}$ increases exponentially: after only 5 coalescence events the final $n_{\text {agg }}$ of a few hundreds is reached.

With the presence of PEGA units, the situation is quite different. In these cases, an attractive well is observed on the interaction profiles (see Figure 3b-d). These energy minima appear at a higher separation (i.e. greater distance between the center of mass of the micelle) when the PEG side chains are located further away from the hydrophobic core. TThe radialdensity function of the PEG monomers around the micelle center of mass for the differentcopolymers are given in supplementary material (see Figure S6) and confirms that this attraction is in fact due to PEG-PEG interactions. The approximate values of these attractive wells are reported in Table 1 . The presence of this attractive well leads to a completely 

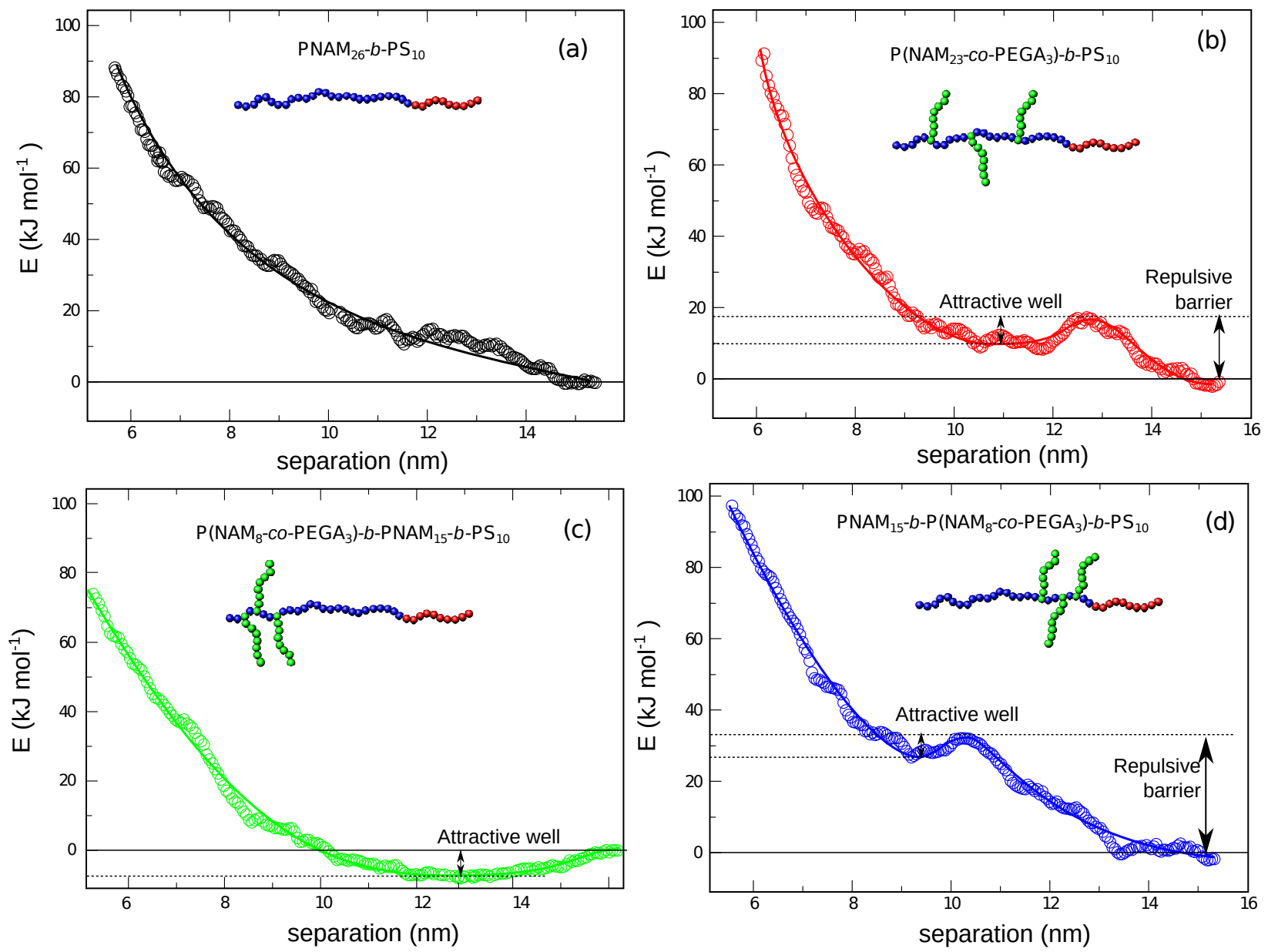

Figure 3: Potential of mean force (E) curves between two copolymer micelles having various hydrophilic block architectures. 
different mechanism compared to the pure PNAM hydrophilic block $\left(\mathrm{PNAM}_{26}-b-\mathrm{PS}_{10}\right)$. In the presence of an attractive interaction between PEG segments, the small micelles could stick together upon collision and thus lead to the formation of small clusters. The swelling of the micelles within these clusters will then lead to their coalescence into more complex structures, such as vesicles, the interstitial water of the cluster forming the core of the vesicle.

Table 1: Values of repulsive barrier and attractive well from the various copolymers architecture.

\begin{tabular}{cccc}
\hline & $\begin{array}{c}\text { Repulsive barrier } \\
\left(\mathrm{kJ} \cdot \mathrm{mol}^{-1}\right)\end{array}$ & $\begin{array}{c}\text { Attractive well } \\
\left(\mathrm{kJ} \cdot \mathrm{mol}^{-1}\right)\end{array}$ & Final morphology $^{a}$ \\
\hline $\mathrm{PNAM}_{26}-b-\mathrm{PS}_{10}-b-\mathrm{PS}_{10}$ & $/$ & $/$ & spheres \\
$\mathrm{P}\left(\mathrm{NAM}_{23}-c o-\mathrm{PEGA}_{3}\right)-b-\mathrm{PS}_{10}$ & 17 & 10 & small vesicles $^{b}$ \\
$\mathrm{P}\left(\mathrm{NAM}_{8}-c o-\mathrm{PEGA}_{3}\right)-b-\mathrm{PNAM}_{15}-b-\mathrm{PS}_{10}$ & 0 & 8 & small vesicles $^{b}$ \\
$\mathrm{PNAM}_{15}-b-\mathrm{P}\left(\mathrm{NAM}_{8}-c o-\mathrm{PEGA}_{3}\right)-b-\mathrm{PS}_{10}$ & 32 & 5 & large vesicles \\
\hline
\end{tabular}

${ }^{a}$ From ref Lesage et al. ${ }^{b}$ Structures also observed: fibers and tubular cylinders.

With the PEG side chains located statistically along the PNAM block or close to the polystyrene block, a repulsive barrier followed by an attractive well are observed (see Figure $3 \mathrm{~b}$ and $\mathrm{d}$, respectively). One striking figure in Table 1 is the fact that large vesicles are obtained for the highest repulsive barrier and the lowest attractive well. (cf. Table 1, line 4) From this information, the mechanism envisioned above can also be used to explain the different sizes of the final vesicles. The height of this repulsive barrier as well as the depth of the attractive well will impact the aggregation kinetics. When the interaction potential between the particles is purely attractive (cf. Table 1, line 3), the aggregation process is solely limited by mutual diffusion (or Brownian motion) of the particles, and one refers to diffusion limited cluster aggregation (DLCA). ${ }^{56}$ This is the case for the $\mathrm{P}\left(\mathrm{NAM}_{8}-c o-\mathrm{PEGA}_{3}\right)-b-\mathrm{PNAM}_{15}-b$ $\mathrm{PS}_{10}$ copolymer, a fast aggregation occurs, leading to loose and ramified structures which can break down into small vesicles or long fiber-like structures. Similar mechanism may 
occur with the $\mathrm{P}\left(\mathrm{NAM}_{23}-c o-\mathrm{PEGA}_{3}\right)-b$ - $\mathrm{PS}_{10}$ copolymers considering the relatively low value of the energy barrier and the relatively high value of the attractive well (cf. Table 1, line $2)$. However, in the case of $\mathrm{PNAM}_{15}-b-\mathrm{P}\left(\mathrm{NAM}_{8}-c o-\mathrm{PEGA}_{3}\right)-b-\mathrm{PS}_{10}$, a high repulsive barrier is present between the particles (cf. Table 1, line 4). The aggregation is slowed down by the fact that numerous attempts will be necessary to overcome this barrier, and one refers to slow or reaction limited cluster aggregation (RLCA) leading to denser clusters capable of trapping large amount of water, hence the formation of large vesicles. ${ }^{56}$

(a)
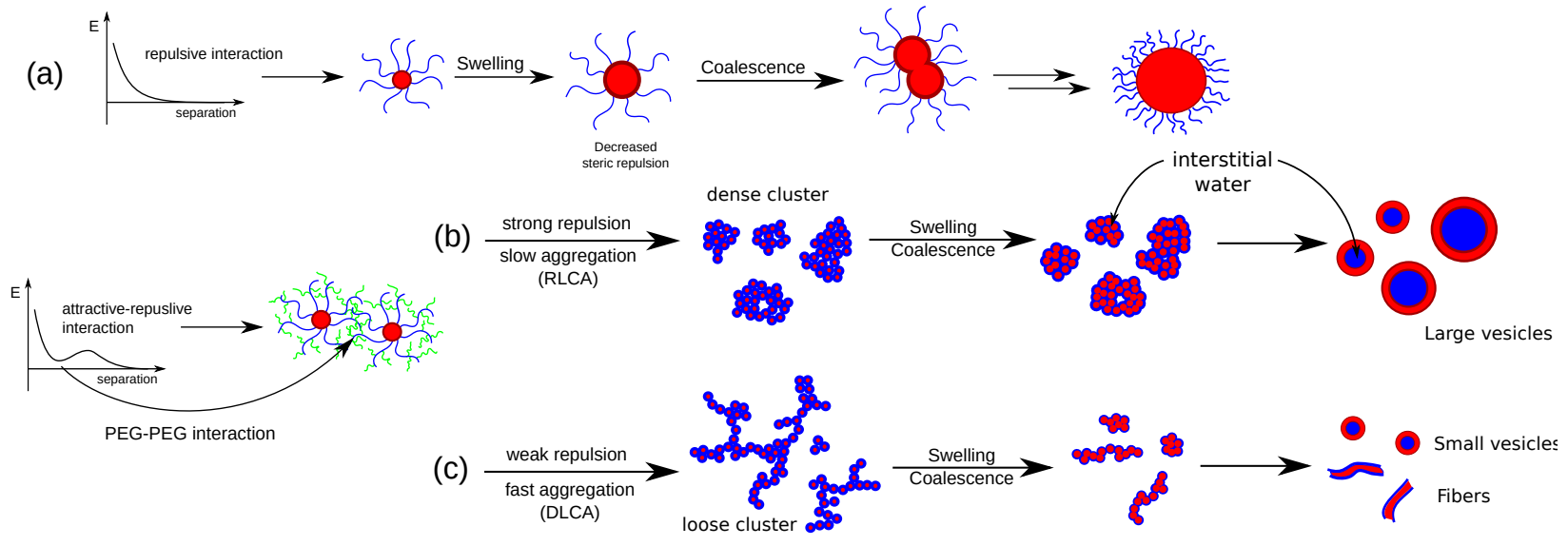

Figure 4: Illustration of the cluster aggregation mechanism during polymerization-induced self-assembly. (a) Repulsive interaction occurring with pure PNAM macroRAFT ; (b) and (c) Attracto-repulsive interaction occurring with the introduction of PEGA units. Depending on the position of the PEGA units a strong (b) or weak (c) repulsive barrier was observed, which impacts the aggregation kinetics and thus the final morphologies.

This mechanism suggests that cylindrical and vesicular morphologies are the results of the aggregation of copolymer micelles into clusters containing interstitial water. This clusteraggregation is likely caused by the lower water solubility of PEG segements with increasing temperature. Here, we have explained how the position of the PEG segements can directly impact the interaction between micelles and therefore modify the aggregation kinetics. The aggregation rate determines the structure of these clusters of aggregated-micelles and thus the final morphologies. A rather strong attractive interaction (i.e. small repulsive barrier) could explain the formation of strings of particles, which can then coalesce as a fiber-like 
structure as hypothesised by Armes and co-workers. ${ }^{25} \mathrm{~A}$ weak attractive interaction (i.e. stronger repulsive barrier) will lead to denser clusters capable of trapping interstitial water during coalescence, hence forming large vesicles. One should note that in this case the coalescence rate will decrease and the diffusional growth will become predominate. However, as the micelle size is increased by swelling with monomer, the repulsion barrier decreases as the number of the polymer chains per surface unit decreases. Therefore, micelle/micelle coalescence still occurs alongside diffusional growth.

This scenario can also explain the discrepancy between the obtained morphology and the packing parameter. ${ }^{27}$ Indeed, the PEG segments is often contributing to the hydrophilic block in the calculation of the packing parameter which might be problematic considering the loss of solubility of PEG with increasing temperature. More generally, this work points out the limitation of the packing parameter for complex copolymer architectures in which hydrophilic and hydrophobic blocks cannot be easily segregated. The packing parameter focuses mainly on the size of the block while the interaction between them is overlooked. Recent simulation results, using Dissipative particle dynamics (DPD), show that the interactions between the blocks and the solvent could influence the morphology in a PISA process. ${ }^{57}$ The authors observe the formation of "porous vesicles" with decreasing solubility between the hydrophilic block and the solvent. Furthermore, Lovett et al. examine the gelation behavior exhibited by diblock copolymer worms using small-angle X-ray scattering and percolation theory. ${ }^{58}$ They proved that the gelation occurs via multiple contacts between neighbouring worms, rather than as a result of worm entanglements. This suggests the existence of an attractive interaction between network junctions required for gelation. This mechanism is also supported by a thorough review of the existing literature on emulsion PISA, which shows that non-spherical morphologies are often obtained in emulsion PISA using a slight hydrophobicity within the hydrophilic block. In many cases, PEG branches are used to bring hydrophobic interactions in the hydrophilic block when the temperature is raised. ${ }^{14,59-66}$ 
Qiao et al. used brush-type copolymers with PEG side chains of various lengths and extended with butyl methacrylate and styrene as hydrophobic monomers. ${ }^{59}$ They observed a drastic change in particle morphology (from spheres to vesicles and anisotropic objects) when varying the $\mathrm{pH}$ and the ionic strength whihe both impact the solubility of hydrophilic segment (i.e. increase hydrophobicity). Zhang X. et al. synthesized poly(methacrylic acidco-poly(ethylene glycol) methyl ether methacrylate) (P(MAA-co-PEGMA)) copolymers selfassembled upon chain extension with styrene. ${ }^{60}$ At $\mathrm{pH}$ 7, only spheres were obtained, most likely due to a strong electrostatic stabilization imparted by the high ionization degree of the methacrylic acid units. ${ }^{61}$ At $\mathrm{pH} 5$, the decreased electrostatic repulsion makes the P(MAAco-PEGMA) more hydrophobic thus leading to non-spherical morphologies (fibers and vesicles). ${ }^{14}$ Finally at $\mathrm{pH} 3$, the strong hydrophobic character of the carboxylic acid/ethylene glycol complex does not allow a good segregation strength between the blocks and spherical particles were obtained, but with some of the hydrophilic segments buried into the polymer core. Boissé et al. reported the formation of long filaments or vesicle-like structures using emulsion PISA of styrene with macroRAFT agents including acrylic acid and poly(ethylene glycol) arcylate units. ${ }^{62,63}$ Charged carboxylic groups $(\mathrm{pH}=8)$ provided sufficient repulsion and spheres were formed. However, the addition of $\mathrm{CaCl}_{2}$ led to the formation of fibers and vesicles due to the ionic crosslinking of carboxylic acid groups with $\mathrm{Ca}^{2+}$. Truong et al. have reported the formation of worms, vesicles and lamellae prepared by emulsion polymerization of styrene using thermosensitive copolymer (i.e. poly(di(ethylene glycol)ethyl ether methacrylate- $c o-N$-(2-hydroxypropyl) methacrylamide)). ${ }^{64-66}$ Non-spherical shapes were obtained by cooling down the hot latex from $70{ }^{\circ} \mathrm{C}$ to ambient temperature in the presence of toluene to plasticize the polystyrene core. The decrease of the temperature changes the hydrophilicity of the thermosensitive block which drives the restructuring of the diblock copolymer assemblies into different morphologies. Finally, Khor et al. used a hydrophilic block composed of $N$-hydroxyethyl acrylamide and short poly(ethylene glycol) acrylate. ${ }^{67}$ They increased the hydrophobicity of this hydrophilic block by substituting the carboxylic 
acid end-group with a methyl ester group, which led to the formation of vesicles. This result demonstrates the importance of a slight increase of hydrophobicity within the hydrophilic block in order to form vesicles in emulsion PISA. All these examples demonstrate that the formation of non-spherical objects in emulsion PISA usually requires the introduction of an attractive interparticle interaction often provided by the increase hydrophobic character of PEG with the temperature. ${ }^{59,64-66}$ In some cases, this attractive interaction was also assisted by ionic complexation, ${ }^{62,63}$ or counter-balanced by the electrostatic repulsion from pH-sensitive charged groups ${ }^{14,60,61}$ in order to tune the morphology. However, non-spherical morphologies, obtained using emulsion PISA, were also reported without the use of PEGbased copolymer. ${ }^{68-71}$

Groison et al. used copolymer of methacrylic acid with $8.8 \mathrm{~mol} \%$ of styrene sulfonate for the hydrophilic segment and methyl methacrylate (MMA) and styrene for the hydrophobic one. ${ }^{69}$ In this case, because of the relatively high solubility $\left(0.15 \mathrm{~mol} \cdot \mathrm{L}^{-1}\right)$ of MMA at 80 ${ }^{\circ} \mathrm{C}$, the diffusional growth will again be much faster than the coalescence rate. Furthermore, the solubility difference between the styrene and MMA will induce a monomer composition gradient within the hydrophobic block, resulting in a hydrophilic-intermediate-hydrophobic polymer structure. This intermediate segment can provide an attractive interparticle interaction similar to PEG segments. The same interpretation could be done regarding the work of Ratcliffe et al. ${ }^{70}$ and Mable et al. ${ }^{71}$ since they both used triblock copolymers with similar structure (i.e. hydrophilic-intermediate-hydrophobic). Ratcliffe et al. used an intermediate poly(2-hydroxyethyl methacrylate) (PHEMA) block. PHEMA is often described as a hydrophilic polymer due to is ability to form hydrogel by swelling up to $40 \%$ of water. ${ }^{72,73}$ However, the fact that it swells rather than dissolves in water proves that water is a poor solvent for the PHEMA as show by it relatively high Flory parameter $(0.77<\chi<0.83) .{ }^{74-76}$ Furthermore, swelling of PHEMA is due to intra- and intermolecular hydrogen bonding with water which weakens with increasing temperature. ${ }^{77}$ Similarly Mable et al. used a triblock copolymer: poly(glycerol monomethacrylate)-co-poly(2-hydroxypropylmethacrylate)- 
co-poly(benzyl methacrylate) (PGMA-PHPMA-PBzMA). Here the intermediate segment is made of HPMA, an hydrophilic monomers (solubility around $0.9 \mathrm{~mol} \cdot \mathrm{L}^{-1}$ ), which gives upon polymerization an hydrophobic segment. ${ }^{78}$ In fact, both PHPMA and PHEMA are hydrophobic enough to prepare latexes by aqueous dispersion polymerization. ${ }^{79}$ Interestingly, these triblock (hydrophilic-intermediate-hydrophobic) copolymers can be viewed as intermediates cases between emulsion and dispersion PISA and can be used to expand our interpretation. In the case of PISA in dispersion, the water-soluble monomer grows as an hydrophobic coreforming block. But a small portion of this segment located close to the hydrophilic block could remain partially soluble/hydrated and thus create an attractive interaction between copolymer micelles. This attractive interaction leading to their aggregation and the formation of non-spherical morphology.

More generally there seems to be a consensus as to the mechanism of formation of nanoobjects using emulsion and dispersion PISA. Small spherical micelles appear at small conversion followed by their transformation into fibers then to vesicles with increasing conversion. ${ }^{25,26,69}$ This could be rationalized in accordance with the proposed mechanism: at low conversion, stables micelles are formed and remain spherical because of the dense hydrophilic corona (i.e. surface is saturated with surfactant) and the high mobility of the short hydrophobic block, which facilitate the coalescence of the micelles. With increasing conversion, a decreased stability of the micelles and the increased viscosity of the hydrophobic core induce the aggregation of micelles as described above, thus fibers and vesicles are formed. One should note that, in the experiments described in the litterature, the increased conversion (i.e. longer hydrophobic block) is usually obtained by decreasing the concentration of the hydrophilic block. ${ }^{14,25,60,61,69,80}$ Therefore, the transition from fiber to vesicle could be the result of the dilution of the micelles, which slows down their aggregation. More concentrated suspension of micelles gives a faster aggregation creating loose and ramified clusters (i.e. fibers) whereas, at lower concentration, the aggregation rate is slowed down 
hence large and dense clusters are formed (i.e. vesicles). In any case, this morphological transition observed with increasing conversion always requires the presence of a slight hydrophobic segment within the hydrophilic block.

In summary, the observed mechanism of morphological transition can be rationalized considering the aggregation kinetics of the micelles into more or less dense and ramified clus-

ters. The key phenomena controlling the final morphology are the competition between: (i) the diffusional growth rate of the micelles (determined mostly via the hydrophobic monomer solubility) and (ii) the aggregation rate which depends on the concentration of the micelles as well as the interaction profile between them. The first one explains the substantial differences observed between emulsion and dispersion PISA. However, it could also play a role in emulsion PISA with slightly soluble hydrophobic monomers $\left(\approx 0.1 \mathrm{~mol} \cdot \mathrm{l}^{-1}\right)$. The latter determines the aggregation regime and thus the morphology of the clusters of aggregated micelles: loose or dense clusters coalescing into fibers or vesicles, respectively.

\section{Conclusions}

Using umbrella sampling and WHAM algorithm, we calculated the interaction free energy between different self-assembled copolymer aggregates. These simulations were used to propose a new mechanism that explains the change of morphology from spheres to fibers and vesicles depending on the polymer composition and architecture in the case of emulsion PISA. Without PEG branches the hydrophilic block provides strong interparticle repulsion and stable spherical particles are obtained. However, in the presence of PEG branches at 80 ${ }^{\circ} \mathrm{C}$ (the temperature at which the emulsion PISA was performed), the disruption of PEGwater hydrogen bonds leads to a decreased PEG water-solubility and thus an attractive interaction between the copolymer micelles. The position of the PEG branches induces very 
different interaction profiles. Indeed moving the PEG side chains close to the polystyrene block creates a stronger repulsive barrier. The strength of this repulsive barrier controls the aggregation kinetics: a strong repulsive barrier leads to slower aggregation rate and thus larger and denser clusters (RLCA). Theses clusters then coalesce into large vesicles due to the presence of interstitial water molecules in the cluster. Inversely, a weak repulsive barrier causes a rapid aggregation which gives loose and ramified clusters (DLCA) that coalesce after swelling with styrene, leading to tubular nano-structures and small vesicles. This new mechanism approach can provide better control over morphology of the final nano-objects depending on the copolymer composition and architecture for the emulsion PISA.

\section{Acknowledgement}

The authors thank Mr. Claude Bonura and Mr. Nicolas Fuller from the "Centre Commun Informatique et Réseau" CCIR (ICBMS - UMR 5246) for providing computational resources and technical support and Dr. Cyrille Rochas for his help on the ESRF : BM02 - D2AM French CRG Beamline.

\section{Supporting Information Available}

- NAM coarse-grain parametrization

- Estimation of the packing parameters

- Radial density function

\section{References}

(1) Matyjaszewski, K.; Xia, J. Atom transfer radical polymerization. Chem. Rev. 2001, 101, 2921-2990. 
(2) Kamigaito, M.; Ando, T.; Sawamoto, M. Metal-catalyzed living radical polymerization. Chem. Rev. 2001, 101, 3689-3746.

(3) Moad, G.; Rizzardo, E.; Thang, S. H. Radical addition-fragmentation chemistry in polymer synthesis. Polymer 2008, 49, 1079-1131.

(4) Braunecker, W. A.; Matyjaszewski, K. Controlled/living radical polymerization: Features, developments, and perspectives. Prog. Polym. Sci. 2007, 32, 93-146.

(5) Keddie, D. J.; Moad, G.; Rizzardo, E.; Thang, S. H. RAFT agent design and synthesis. Macromolecules 2012, 45, 5321-5342.

(6) Nicolas, J.; Guillaneuf, Y.; Lefay, C.; Bertin, D.; Gigmes, D.; Charleux, B. Nitroxidemediated polymerization. Prog. Polym. Sci. 2013, 38, 63-235.

(7) Jenkins, A. D.; Jones, R. G.; Moad, G. Terminology for reversible-deactivation radical polymerization previously called" controlled" radical or" living" radical polymerization (IUPAC Recommendations 2010). Pure Appl. Chem. 2009, 82, 483-491.

(8) Mai, Y.; Eisenberg, A. Self-assembly of block copolymers. Chem. Soc. Rev. 2012, 41, $5969-5985$.

(9) Zhang, L.; Eisenberg, A. Multiple morphologies of "crew-cut" aggregates of polystyreneb-poly(acrylic acid) block copolymers. Science 1995, 268, 1728-1731.

(10) Israelachvili, J. N.; Mitchell, D. J.; Ninham, B. W. Theory of self-assembly of hydrocarbon amphiphiles into micelles and bilayers. J. Chem. Soc. Faraday Trans. 1976, 72, $1525-1568$.

(11) Antonietti, M.; Förster, S. Vesicles and liposomes: a self-assembly principle beyond lipids. Adv. Mater. 2003, 15, 1323-1333.

(12) Rao, J. P.; Geckeler, K. E. Polymer nanoparticles: preparation techniques and sizecontrol parameters. Prog. Polym. Sci. 2011, 36, 887-913. 
(13) Hayward, R. C.; Pochan, D. J. Tailored assemblies of block copolymers in solution: it is all about the process. Macromolecules 2010, 43, 3577-3584.

(14) Zhang, X.; Boissé, S.; Zhang, W.; Beaunier, P.; D’Agosto, F.; Rieger, J.; Charleux, B. Well-defined amphiphilic block copolymers and nano-objects formed in situ via RAFTmediated aqueous emulsion polymerization. Macromolecules 2011, 44, 4149-4158.

(15) Charleux, B.; Delaittre, G.; Rieger, J.; D'Agosto, F. Polymerization-induced selfassembly: from soluble macromolecules to block copolymer nano-objects in one step. Macromolecules 2012, 45, 6753-6765.

(16) Blanazs, A.; Ryan, A.; Armes, S. Predictive phase diagrams for RAFT aqueous dispersion polymerization: effect of block copolymer composition, molecular weight, and copolymer concentration. Macromolecules 2012, 45, 5099-5107.

(17) Warren, N. J.; Armes, S. P. Polymerization-induced self-assembly of block copolymer nano-objects via RAFT aqueous dispersion polymerization. J. Am. Chem. Soc. 2014, $136,10174-10185$.

(18) Canning, S. L.; Smith, G. N.; Armes, S. P. A critical appraisal of RAFT-mediated polymerization-induced self-assembly. Macromolecules 2016, 49, 1985-2001.

(19) Zhou, J.; Yao, H.; Ma, J. Recent advances in RAFT-mediated surfactant-free emulsion polymerization. Polym. Chem. 2018, 9, 2532-2561.

(20) Lansalot, M.; Rieger, J.; D’Agosto, F. Macromolecular Selfassembly; John Wiley \& Sons, Ltd, 2016; Chapter 2, pp 33-82.

(21) Chaduc, I.; Girod, M.; Antoine, R.; Charleux, B.; D’Agosto, F.; Lansalot, M. Batch emulsion polymerization mediated by poly(methacrylic acid) macroRAFT agents: Onepot synthesis of self-stabilized particles. Macromolecules 2012, 45, 5881-5893. 
(22) Chaduc, I.; Crepet, A.; Boyron, O.; Charleux, B.; D’Agosto, F.; Lansalot, M. Effect of the $\mathrm{pH}$ on the RAFT polymerization of acrylic acid in water. Application to the synthesis of poly(acrylic acid)-stabilized polystyrene particles by RAFT emulsion polymerization. Macromolecules 2013, 46, 6013-6023.

(23) Cunningham, V. J.; Alswieleh, A. M.; Thompson, K. L.; Williams, M.; Leggett, G. J.; Armes, S. P.; Musa, O. M. Poly(glycerol monomethacrylate)-poly(benzyl methacrylate) diblock copolymer nanoparticles via RAFT emulsion polymerization: Synthesis, characterization, and interfacial activity. Macromolecules 2014, 47, 5613-5623.

(24) Chaduc, I.; Reynaud, E.; Dumas, L.; Albertin, L.; D’Agosto, F.; Lansalot, M. From well-defined poly(N-acryloylmorpholine)-stabilized nanospheres to uniform mannuronan-and guluronan-decorated nanoparticles by RAFT polymerization-induced self-assembly. Polymer 2016, 106, 218-228.

(25) Blanazs, A.; Madsen, J.; Battaglia, G.; Ryan, A. J.; Armes, S. P. Mechanistic insights for block copolymer morphologies: how do worms form vesicles? J. Am. Chem. Soc. 2011, 133, 16581-16587.

(26) Brusseau, S.; D’Agosto, F.; Magnet, S.; Couvreur, L.; Chamignon, C.; Charleux, B. Nitroxide-Mediated copolymerization of methacrylic acid and sodium 4styrenesulfonate in water solution and one-pot synthesis of amphiphilic block copolymer nanoparticles. Macromolecules 2011, 44, 5590-5598.

(27) Lesage de la Haye, J.; Zhang, X.; Chaduc, I.; Brunel, F.; Lansalot, M.; D'Agosto, F. The Effect of Hydrophile Topology in RAFT-Mediated Polymerization-Induced SelfAssembly. Angew. Chem. 2016, 128, 3803-3807.

(28) Zhulina, E.; Borisov, O. Theory of block polymer micelles: recent advances and current challenges. Macromolecules 2012, 45, 4429-4440.

(29) Woo, H.-J. Molecular Modeling of Proteins; Springer, 2008; pp 109-120. 
(30) Baştuğ, T.; Chen, P.-C.; Patra, S. M.; Kuyucak, S. Potential of mean force calculations of ligand binding to ion channels from Jarzynskis equality and umbrella sampling. J. Chem. Phys 2008, 128, 04B614.

(31) El Hage, K.; Mondal, P.; Meuwly, M. Free energy simulations for protein ligand binding and stability. Mol. Simulat. 2018, 1-18.

(32) Lee, M. S.; Olson, M. A. Calculation of absolute protein-ligand binding affinity using path and endpoint approaches. Biophys. J. 2006, 90, 864-877.

(33) Kokubo, H.; Tanaka, T.; Okamoto, Y. Prediction of protein-ligand binding structures by replica-exchange umbrella sampling simulations: application to kinase systems. $J$. Chem. Theory Comput. 2013, 9, 4660-4671.

(34) Plazinski, W.; Knys-Dzieciuch, A. The order-to-disorderconformational transition in CD44 protein: An umbrella sampling analysis. J. Mol. Graph. Model. 2013, 45, 122127.

(35) Higo, J.; Ikebe, J.; Kamiya, N.; Nakamura, H. Enhanced and effective conformational sampling of protein molecular systems for their free energy landscapes. Biophys. Rev. 2012, 4, 27-44.

(36) Yonezawa, Y. A method for predicting protein conformational pathways by using molecular dynamics simulations guided by difference distance matrices. J. Comput. Chem. 2016, 37, 1139-1146.

(37) Wang, J.; Shao, Q.; Xu, Z.; Liu, Y.; Yang, Z.; Cossins, B. P.; Jiang, H.; Chen, K.; Shi, J.; Zhu, W. Exploring transition pathway and free-energy profile of large-scale protein conformational change by combining normal mode analysis and umbrella sampling molecular dynamics. J. Phys. Chem. B 2013, 118, 134-143. 
(38) Brunel, F.; Boyron, O.; Clement, A.; Boisson, C. Molecular dynamics simulation of ethylene/hexene copolymer adsorption onto graphene: new insight into thermal gradient interaction chromatography. Macromol. Chem. Phys. 2019,

(39) Berendsen, H. J.; van der Spoel, D.; van Drunen, R. GROMACS: a message-passing parallel molecular dynamics implementation. Comput. Phys. Commun. 1995, 91, 4356.

(40) Hess, B.; Kutzner, C.; Van Der Spoel, D.; Lindahl, E. GROMACS 4: Algorithms for highly efficient, load-balanced, and scalable molecular simulation. J. Chem. Theory Comput. 2008, 4, 435-447.

(41) Pronk, S.; Páll, S.; Schulz, R.; Larsson, P.; Bjelkmar, P.; Apostolov, R.; Shirts, M. R.; Smith, J. C.; Kasson, P. M.; van der Spoel, D. GROMACS 4.5: a high-throughput and highly parallel open source molecular simulation toolkit. Bioinformatics 2013, 29.

(42) Pall, S.; Abraham, M. J.; Kutzner, C.; Hess, B.; Lindahl, E. Tackling exascale software challenges in molecular dynamics simulations with GROMACS. 2014, 3-27.

(43) Marrink, S. J.; Risselada, H. J.; Yefimov, S.; Tieleman, D. P.; De Vries, A. H. The MARTINI force field: coarse grained model for biomolecular simulations. J. Phys. Chem. B 2007, 111, 7812-7824.

(44) Rossi, G.; Monticelli, L.; Puisto, S. R.; Vattulainen, I.; Ala-Nissila, T. Coarse-graining polymers with the MARTINI force-field: polystyrene as a benchmark case. Soft Matter 2011, 7, 698-708.

(45) Lee, H.; de Vries, A. H.; Marrink, S.-J.; Pastor, R. W. A coarse-grained model for polyethylene oxide and polyethylene glycol: conformation and hydrodynamics. J. Phys. Chem. B 2009, 113, 13186-13194. 
(46) Özdemir, C.; Güner, A. Solubility profiles of poly (ethylene glycol)/solvent systems, I: Qualitative comparison of solubility parameter approaches. Eur. Polym. J. 2007, 43, 3068-3093.

(47) Essmann, U.; Perera, L.; Berkowitz, M. L.; Darden, T.; Lee, H.; Pedersen, L. G. A smooth particle mesh Ewald method. J. Chem. Phys 1995, 103, 8577-8593.

(48) Thickett, S. C.; Gilbert, R. G. Emulsion polymerization: State of the art in kinetics and mechanisms. Polymer 2007, 48, 6965-6991.

(49) Berendsen, H. J.; Postma, J. v.; van Gunsteren, W. F.; DiNola, A.; Haak, J. Molecular dynamics with coupling to an external bath. J. Chem. Phys 1984, 81, 3684-3690.

(50) Nosé, S. A unified formulation of the constant temperature molecular dynamics methods. J. Chem. Phys 1984, 81, 511-519.

(51) Hoover, W. G. Canonical dynamics: Equilibrium phase-space distributions. Phys. Rev. A 1985, 31, 1695.

(52) Parrinello, M.; Rahman, A. Crystal structure and pair potentials: A moleculardynamics study. Phys. Rev. Lett. 1980, 45, 1196.

(53) Parrinello, M.; Rahman, A. Polymorphic transitions in single crystals: A new molecular dynamics method. J. Appl. Phys. 1981, 52, 7182-7190.

(54) Huang, F.; Lv, Y.; Wang, L.; Xu, P.; Lin, J.; Lin, S. An insight into polymerizationinduced self-assembly by dissipative particle dynamics simulation. Soft matter $\mathbf{2 0 1 6}$, 12, 6422-6429.

(55) Shupanov, R.; Kos, P.; Gavrilov, A.; Chertovich, A. Modelling Polymerization-Induced Self Assembly (PISA). arXiv preprint arXiv:1901.09345 2019,

(56) Lin, M.; Lindsay, H.; Weitz, D.; Ball, R.; Klein, R.; Meakin, P. Universality in colloid aggregation. Nature 1989, 339, 360. 
(57) Wang, J.; Li, J.; Yao, Q.; Sun, X.; Yan, Y.; Zhang, J. One-pot production of porous assemblies by PISA of star architecture copolymers: a simulation study. Phys. Chem. Chem. Phys. 2018, 20, 10069-10076.

(58) Lovett, J. R.; Derry, M. J.; Yang, P.; Hatton, F. L.; Warren, N. J.; Fowler, P. W.; Armes, S. P. Can percolation theory explain the gelation behavior of diblock copolymer worms? Chem. Sci. 2018, 9, 7138-7144.

(59) Qiao, X.; Lansalot, M.; Bourgeat-Lami, E.; Charleux, B. Nitroxide-mediated polymerization-induced self-assembly of poly(poly(ethylene oxide) methyl ether methacrylate-co-styrene)-b-poly(n-butyl methacrylate-co-styrene) amphiphilic block copolymers. Macromolecules 2013, 46, 4285-4295.

(60) Zhang, W.; DAgosto, F.; Boyron, O.; Rieger, J.; Charleux, B. One-pot synthesis of poly(methacrylic acid-co-poly(ethylene oxide) methyl ether methacrylate)-bpolystyrene amphiphilic block copolymers and their self-assemblies in water via RAFTmediated radical emulsion polymerization. A kinetic study. Macromolecules 2011, 44, 7584-7593.

(61) Zhang, W.; D’Agosto, F.; Boyron, O.; Rieger, J.; Charleux, B. Toward a better understanding of the parameters that lead to the formation of nonspherical polystyrene particles via RAFT-mediated one-pot aqueous emulsion polymerization. Macromolecules 2012, 45, 4075-4084.

(62) Boissé, S.; Rieger, J.; Belal, K.; Di-Cicco, A.; Beaunier, P.; Li, M.-H.; Charleux, B. Amphiphilic block copolymer nano-fibers via RAFT-mediated polymerization in aqueous dispersed system. Chem. Commun. 2010, 46, 1950-1952.

(63) Boissé, S.; Rieger, J.; Pembouong, G.; Beaunier, P.; Charleux, B. Influence of the stirring speed and $\mathrm{CaCl} 2$ concentration on the nano-object morphologies obtained via 
RAFT-mediated aqueous emulsion polymerization in the presence of a water-soluble macroRAFT agent. J. Polym. Sci. Pol. Chem. 2011, 49, 3346-3354.

(64) Truong, N. P.; Whittaker, M. R.; Anastasaki, A.; Haddleton, D. M.; Quinn, J. F.; Davis, T. P. Facile production of nanoaggregates with tuneable morphologies from thermoresponsive P (DEGMA-co-HPMA). Polym. Chem. 2016, 7, 430-440.

(65) Truong, N. P.; Quinn, J. F.; Anastasaki, A.; Rolland, M.; Vu, M. N.; Haddleton, D. M.; Whittaker, M. R.; Davis, T. P. Surfactant-free RAFT emulsion polymerization using a novel biocompatible thermoresponsive polymer. Polym. Chem. 2017, 8, 1353-1363.

(66) Truong, N. P.; Zhang, C.; Nguyen, T. A.; Anastasaki, A.; Schulze, M. W.; Quinn, J. F.; Whittaker, A. K.; Hawker, C. J.; Whittaker, M. R.; Davis, T. P. Overcoming surfactantinduced morphology instability of noncrosslinked diblock copolymer nano-objects obtained by RAFT emulsion polymerization. ACS Macro Lett. 2018, 7, 159-165.

(67) Khor, S. Y.; Truong, N. P.; Quinn, J. F.; Whittaker, M. R.; Davis, T. P. Polymerizationinduced self-assembly: The effect of end group and initiator concentration on morphology of nanoparticles prepared via RAFT aqueous emulsion polymerization. ACS Macro Lett. 2017, 6, 1013-1019.

(68) Delaittre, G.; Dire, C.; Rieger, J.; Putaux, J.-L.; Charleux, B. Formation of polymer vesicles by simultaneous chain growth and self-assembly of amphiphilic block copolymers. Chem. Commun. 2009, 2887-2889.

(69) Groison, E.; Brusseau, S.; D'Agosto, F.; Magnet, S.; Inoubli, R.; Couvreur, L.; Charleux, B. Well-defined amphiphilic block copolymer nanoobjects via nitroxidemediated emulsion polymerization. ACS Macro Lett. 2011, 1, 47-51.

(70) Ratcliffe, L. P.; Blanazs, A.; Williams, C. N.; Brown, S. L.; Armes, S. P. RAFT polymerization of hydroxy-functional methacrylic monomers under heterogeneous conditions: effect of varying the core-forming block. Polym. Chem. 2014, 5, 3643-3655. 
(71) Mable, C.; Thompson, K.; Derry, M.; Mykhaylyk, O.; Binks, B.; Armes, S. ABC triblock copolymer worms: synthesis, characterization, and evaluation as pickering emulsifiers for millimeter-sized droplets. Macromolecules 2016, 49, 7897-7907.

(72) Wichterle, O.; Lim, D. Hydrophilic gels for biological use. Nature 1960, 185, 117.

(73) Macret, M.; Hild, G. Hydroxyalkyl methacrylates: kinetic investigations of radical polymerizations of pure 2-hydroxyethyl methacrylate and 2, 3-dihydroxypropyl methacrylate and the radical copolymerization of their mixtures. Polymer 1982, 23, 81-90.

(74) Mikos, A. G.; Peppas, N. A. Flory interaction parameter $\chi$ for hydrophilic copolymers with water. Biomaterials 1988, 9, 419-423.

(75) Mark, J. E. Polymer data handbook. 2009,

(76) Rapado, M.; Peniche, C. Synthesis and characterization of pH and temperature responsive poly(2-hydroxyethyl methacrylate-co-acrylamide) hydrogels. Polímeros 2015, 25, $547-555$.

(77) Sung, Y.; Gregonis, D.; John, M.; Andrade, J. Thermal and pulse NMR analysis of water in poly(2-hydroxyethyl methacrylate). J. Appl. Polym. Sci. 1981, 26, 3719-3728.

(78) Ali, A. I.; Pareek, P.; Sewell, L.; Schmid, A.; Fujii, S.; Armes, S.; Shirley, I. Synthesis of poly(2-hydroxypropyl methacrylate) latex particles via aqueous dispersion polymerization. Soft Matter 2007, 3, 1003-1013.

(79) Chu, H.-H.; Fu, D.-C. Preparation of poly(hydroxyethyl methacrylate) and poly(hydroxypropyl methacrylate) latices. Macromol. Rapid Commun. 1998, 19, 107110.

(80) Zhang, W.; D’Agosto, F.; Dugas, P.-Y.; Rieger, J.; Charleux, B. RAFT-mediated one-pot aqueous emulsion polymerization of methyl methacrylate in presence of 
poly(methacrylic acid-co-poly(ethylene oxide) methacrylate) trithiocarbonate macromolecular chain transfer agent. Polymer 2013, 54, 2011-2019. 


\section{Graphical TOC Entry}

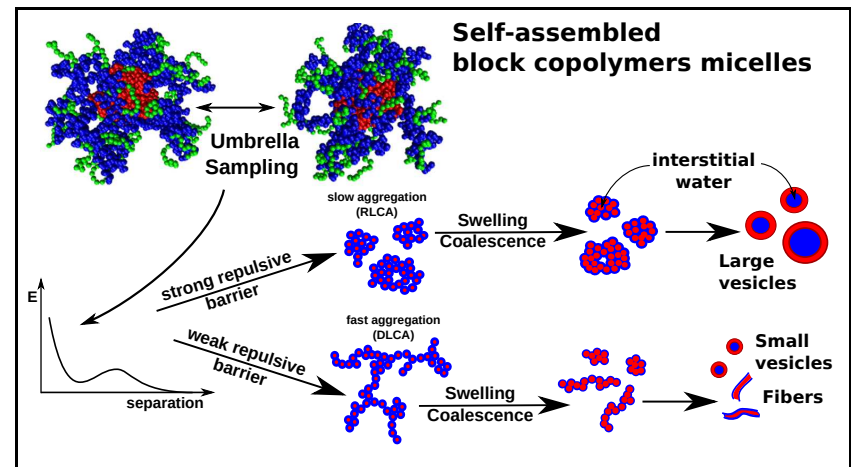

